\title{
THE STRATEGY OF USING PERSUASIVE ESSAY IN ENGLISH FOR MEDICAL ACADEMIC WRITING
}

\author{
Elli Setiyo Wahyuni \\ Hang Tuah University Surabaya
}

\begin{abstract}
.
Writing persuasive essay has the purpose of providing some techniques in organizing the idea and constructing the sentences in coherence. The content of this essay contains the health issue and medical terms. The students of medical faculty are expected to make a good persuasive essay in order to find out the recommendation solution of a health problem through the strategies (1) brainstorming (2) mapping (3) the 5 W's (4) setting thesis statement (5) providing fact, statistic, and example (5) conclusion. The techniques have improved the student writing as the essays have been evaluated and given positive input on the content and development of paragraphs. This academic writing aims to give some practices for the Medical Faculty students of Hang Tuah University in order to produce a good persuasive essay in term of coherence, sentence structure, and organization.
\end{abstract}

Keywords: Brainstorming, Mapping, The 5W's, Persuasive essay.

English is defined as Lingua Franca which means a language communication generally used for the communication between the speakers of second language acquisition (Harmer, 2002). The target of mastering the second language for the students who consider English as the second language acquisition is able to write and speak well. It is a fact that mastering language needs practice in all skills. A student can't be said as a master in English by improving only one language skill, as a result an English learner should able to use spoken and written language. For instance, mastering grammatical order, sentence construction and coherence are needed in writing an academic essay. Using the right pronunciation, spelling, and expression are required in speaking. Therefore, a learner must be given some practices in order to enhance the comprehension of those components.

The students of Medical Faculty as the object of the research assume that academic writing is as important as speaking. The reason of writing becomes substantial because the need for research paper, final project and another academic purposes. Thus, they are also asked to make journal paper or thesis at the end of semester. Some students may feel reluctant to write as they are lack of knowledge in 
vocabulary mastery and skills in organizing sentences into chronological order and coherence. The students who are studying in medical faculty have been targeted to comprehend the reading text, write an essay, and speak fluently. Here, the target of mastering academic writing is analyzed to find out the impact of writing strategy in improving the student writing essay.

Writing is also assumed as written communication because people independently share what they have thought and done through writing forms (Bennie, 2009). Thus, the writers give the positive values or news to the readers who directly give respond. This term is usually used as discussion in teaching English in the classroom. Writing English for SLA is considered to be a challenging since the teachers should apply some techniques in which they convey the material meaningfully. Otherwise, the learners feel bored and reluctant to do the exercises. There are various exercises which improve the ability of writing essay. There are various type of essays, one of suggested essays which is used to influence someone to believe or do something is persuasive essay. This kind of essay is suitable for medical student writing since they are asked to create one idea of a medical topic and able to convince the reader using logic argument and reason to make them follow the suggested points in the essay.

The first step in making academic persuasive essay is organizing the ideas which are benefit for the writer to develop a good framework. Thus, the strategy of persuasive writing leads the writing process becomes a successful essay and meaningful for the readers. Persuasive writing strategies can also be used effectively when the students are faced a number of possible essay topics and must determine the best technique to express their argument, opinion and experiences. The application of this learning process needs the cooperation between teacher and student to reach the goal of autonomous language activity (Smith, 2001). The key point in the process is the flow and the speed to keep writing. The goal of writing persuasive essay for University level students is to convey the information and knowledge about scientific. When the essay is clear and accurate, the readers will understand easily the content and the topic discussed when the writer organizes them accurately and clearly (McCarthy, 1998). 
It is a fact that a writer needs both organization on the ideas and good planning on the writing. Good planning will structure time and keep on track, but most important is what actually goes in the essay. Planning an essay offers a way to explore a topic by balancing what a marker wants with the effort that a student needs to put in to achieve the grade they expect. Creating a good essay using a good planning need the balances between the relevance topic and the content that the students want to tell. In addition, relevance content refers to the significant association between the topic and what is being written. In order to have the relevance topic, content and good planning in writing, a persuasive essay should use following steps (Rao, 2007).

(1). Choose the topic. Which side of the issue or problem are going to write about, and what solution

will be offered? What is the purpose of the essay?

(2). Analyze the audiences. Decide if the audience agrees with, neutral, or disagrees with the writer

position.

(3). Analyze the topic. A persuasive essay must provide specific and convincing evidence. The writer

should has creative and critical thinking.

(4). Organize the essay. Figure out what evidence, examples and supporting details will be included and

in what order the purpose and topic will be presented.

The stages of essay writing in finding the relevance content are classified as analyzing, evaluating, creating, remembering, and understanding (Anderson \& Krathwohl, 2001). Writing requires process and skills that take much time, effort, and critical thinking. The students create the topic, analyze the idea, write the phrases, sentences and discover the finding. Writing is a process of organizing the ideas and applying the stages in order to get the benefit for the future writing level. A persuasive essay is an essay used to convince a reader about a particular idea. The writer takes a position for or against an issue and writes to convince the reader to believe or do something. Persuasive writing is often used in advertisements to get 
the reader to buy a product, and other types of writing to get the reader to accept a point of view. In order to convince the reader, it needs facts or examples. Persuasive writing is also known as the argument essay which develops logical thinking and point of view and shows that an idea on certain topic is reasonable. It attempts to persuade a reader to use a certain point of view or to take a specific action. The argument must always use relevant reasons and solid evidence by stating facts, giving logical explanation, examples, and suggestion promoted by the expert.

The language target is fulfilled when the students of Medical faculty become proficient in academic writing. The proficiency in language skill through the strategy of persuasive writing is expected to be beneficial to the student writing improvement (Starkey, 2004). The keys to successful writing should use the following guidelines.

(1). Stating a firm opinion that can influence the reader point of view

(2). Starting the idea with a grabber or hook to get the reader's attention.

(3). Providing evidence to support the opinion.

(4). Formulating the finding in conclusion to make the readers believe in the new perspective.

The strategy of writing persuasive essay requires some techniques to have a good writing. The use of writing in English for Medical Faculty students means to give impacts for the students writing analysis and the tasks in the classroom activity. These are the strategies from the starting point to the final finding of the ideas (Starkey, 2004).

\section{(1). Brainstorming}

Brainstorming is an exercise of flowing some ideas which meant to include many thoughts and ideas on a given topic. The technique contains various individual thoughts or ideas that are linked together by association with previous ideas. Putting the ideas in sentences or phrases to paper will be helpful because the goal is established into a point of view on a topic and support the content. 


\section{(2). Mapping}

The concept in mapping is organizing the ideas using visual graphic which is easier for the students to investigate the connections between various ideas in mind. The step in mapping is simply putting the main idea in a box or circle in the middle and connected by arrows to show the relationships between each boxes and to develop some ideas. The sample of mapping concept as follows

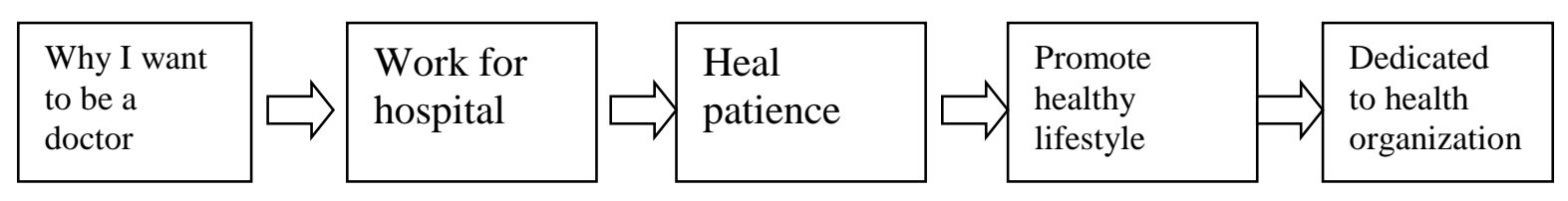

(3). The 5 W's

The 5 W's means asking "who, what, where, when, and why" to get a complete statement. This technique is useful for choosing an essay topic and for focusing a topic that has been selected. The 5 W's should be done deliberately with great thought given to each question in which every idea that comes to mind shouldn't be included, and concentrate on the standard W's: Who, What, Where, When, and Why." These questions will help the learner to quickly develop a great deal of information about the subject. The 5 W's contribute some suggestions to the essay.

(1). who: who is involved? at what level? who is affected?

(2). what: what is your topic? what is its significance? what is at stake? what are the

issues?

(3). where: where does your subject occur? where is its source?

(4). when: when does your topic occur? when did it begin/end? when must action

be taken to deal with it?

(5). why: why is it our subject of interest? why did it develop as it did? why should

other be interested in your topic?

(4). Starting the Introduction. 
Introduction in an essay has a purpose to get the reader's attention. The thesis statement of persuasive essay used in medical academic writing is opened with strong sentence in which the aim is to influence the reader to believe the opinion or fact. The thesis statement will tell the specific topic of an essay, impose manageable limits on a certain topic, and suggest the organization of the paper. The example of strong statement in Persuasive writing as follows.

[Grabber-opening with a strong statement]Of all the problems facing the environment today, the one that bothers me the most is global warming. Some scientists say that the earth is getting warmer because of the greenhouse effect. [Thesis statement] In this paper I will describe the greenhouse effect and whether the earth's atmosphere is actually getting warmer.

(5). Providing relevant Body of paragraph.

The Body of Persuasive writing includes some evidences to support the opinion offered in the thesis statement of the Introduction. The Body should consist of at least three paragraphs. Each paragraph is based on a solid reason to show the relevance with the thesis statement. A good persuasive writer is recommended to anticipate opposing viewpoints and provide arguments along with the main points in the essay. To provide a reasonable argument, the paragraphs in the Body should use the elaboration in form of statistics, research, real-life experience, fact, and examples. Below is the example of the body of paragraph.

[Opposing viewpoint] President George W. Bush, oil-industry leader and others believe that Americans will benefit from the oil that lies under the snow-filled surface of the refuge. In their opinion, the oil will help reduce high fuel prices and decrease our need for oil from other countries.

[Opinion] I believe the cost of such drilling is too high. [Fact and research] I agree with environmentalists who fear that drilling will disturb the migration of more than 130,000 Caribou. Each spring, the Caribou travel 400 miles to give birth on the coastal plain. In this area of the refuge, there are fewer predators. In addition, experts say that the oil in the area adds up to less than a six-month supply. Is such a small amount of oil worth the risk drilling poses to these animals?

(6). Recommendation conclusion. 
A piece of persuasive writing usually ends by summarizing the most important details of the argument and stating what the reader believe or do. The conclusion enables the reader to recall the main points or position. Recommendation conclusion is formed when summarizing the main points then stressing the actions or remedies that should be taken. Writing English for medical purposes should promote some advices for the reader to follow most suitable finding.

[Recommendation conclusion] Americans are the largest consumers of oil. Instead of drilling for oil, we should decrease our need for foreign oil simply by using less. We must all work together to cut back on the oil we use in order to preserve the wild life of the Arctic National Wildlife refuge.

People are constantly examining their surroundings and concluding whether or not things are useful or effective. In short, people, places, objects or situations are constantly being evaluated and an opinion is being formed about them. Evaluation is a decision made based upon the information gathered through assessment (Stiggins, 1996). This is what an evaluation essay requires a writer to do: present a clear, balanced evaluation of a subject in an attempt to have the audience agree with the writer's point of view. It is a fact that the students need to be evaluated especially their writing performances. Some students may prefer to be corrected in term of language use, vocabulary, and the organization of the paragraphs, but some may ask for the content input. However, the lecturer can't justify that a certain writing part is the most recommended to be evaluated, a lecturer may use content input instead of grammar correction. Correction is the information given to the learner following the learning process with the aim to develop performance (Zainuddin, 2004).

The application of correction can be different based on teachers' preferences, the writing task they have set and also the effect they expect to create (Hyland, 2003). The evaluation may depend on the students need and what should be improved. Medical faculty students are categorized as advanced students who already master grammatical and vocabulary usage. The evaluation which they need is the content of writing essay. Furthermore, the evaluation should be reasonable and logically to support the point of view. The use of logical input will help the student 
react to the judgment on the evaluation sheet and may consider it is suitable for them. In addition, it is crucial to respond student writing especially on both content and organization of the ideas (Ferris, 2002). Below is the evaluation check list to give input on the student writing content and the organization of the idea.

Table 1

\section{Evaluation Essay Checklist}

\begin{tabular}{|l|l|}
\hline$\sqrt{ }$ & \multicolumn{1}{|c|}{ EVALUATION ESSAY CHECKLIST } \\
\hline & $\begin{array}{l}\text { Has the impression about the subject been determined using reasonable } \\
\text { criteria? }\end{array}$ \\
\hline & $\begin{array}{l}\text { Is the topic clearly stated in the thesis statement, and does it reflect the } \\
\text { impression made? }\end{array}$ \\
\hline & $\begin{array}{l}\text { Are the content of essay logical? Are there any fact, data statistic and } \\
\text { example? }\end{array}$ \\
\hline & $\begin{array}{l}\text { Are the sentences put in coherence? Are the ideas arranged in } \\
\text { chronological order? }\end{array}$ \\
\hline & Does the conclusion state the solution and recommended findings? \\
\hline
\end{tabular}

\section{Methodology}

\section{The sample}

The medical faculty students who write persuasive essay as individual task, use the strategy of writing persuasive essay which is introduced by the lecturer. There are 25 samples of student essay which have been analyzed and evaluated. The evaluation standard used by the lecturer gives input on content and organization of the ideas.

\section{The procedure}

There are twenty five students who take English subject on the first semester are instructed to apply the technique of writing Persuasive essay. The technique promotes six strategies to make a good writing result. The student essay is evaluated using the chart of evaluation essay checklist in order to investigate the benefit of writing strategy for academic purposes.

(1). Finding out an interesting issue on health problem (brainstorming)

(2). Categorizing some ideas to get one suitable topic (mapping)

(3). Connecting the relevance between the topic and the 5 W's question.

(4). Starting the introductory paragraph with a strong sentence and thesis statement

(5). Providing a relevance evidence, view points, fact, and statistic to support the body of paragraph.

(6). Writing the ending of paragraph by giving a recommendation or solution of the topic. 
The strategies above are expected to give a very clear instruction for the writing steps. One procedure can't be separated with another part. This is a chronological order from starting a topic to creating a conclusion. The stages will be put in order by using a writing template given by the lecturer. The function of using writing template is to make the easiest way of putting the ideas and organizing the sentences in a rough draft. The purpose of providing a writing template is to know the student writing process from the beginning point of finding the topic and organizing the sentences in coherence. In addition, the lecturer will easily recognize that the students apply the strategy and the draft will show how the students put the ideas.

Table 2

Writing Template

\begin{tabular}{|ll|l|}
\hline & \multicolumn{1}{c|}{ WRITING TASK } \\
\hline & The strategy & Name: \\
\hline 1. & Brainstorming & \\
\hline 2. & Mapping & \\
\hline 3. & The 5 WS & \\
\hline 4. & Introduction & \\
\hline 5. & Body & \\
\hline 6. & Conclusion & \\
\hline
\end{tabular}

\section{Results}

Writing is very important in education today so everyone wants to know the best way to teach it.

But that can be a challenge because there are so many different ideas out there (Daniels, 1999). The significant of English for medical purposes has been a major focus in learning how to write a good essay. The result of using the strategy of persuasive essay in academic writing shows a significant impact. Furthermore, writing with context can make students able to develop analysis when they write a reasonable paragraph and make the readers give their expectation easier. In other words, if the students know what to write, what the reader expects from the text, and which parts of the language system that are relevant to the particular task in a given context, then they will be able to develop their analysis in writing a reasonable paragraph and have a good chance to write something (Johnson, 2002). The example below is one of student writing results.

Table 3

Student Writing Draft 


\begin{tabular}{|c|c|c|c|}
\hline \multicolumn{4}{|c|}{$\begin{array}{l}\text { WRITING TASK } \\
\text { PERSUASIVE ESSAY }\end{array}$} \\
\hline The strategy & \multicolumn{3}{|c|}{ Name: Student A } \\
\hline 1. Brainstorming & \multicolumn{3}{|c|}{ Health problem ......??? diseases ... a smoker $\rightarrow$ lung cancer... } \\
\hline 2. Mapping & 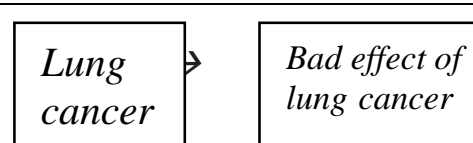 & $\begin{array}{l}\text { Smoker } \\
\text { has lung }\end{array}$ & $\begin{array}{l}\text { The bad effect of } \\
\text { cigarette smoking }\end{array}$ \\
\hline 3. The $5 \mathrm{WS}$ & \multicolumn{3}{|c|}{$\begin{array}{l}\text { Who: the reader is young people (men and women) } \\
\text { What: the bad effect of cigarette smoking } \\
\text { Where: at school, at home, public places } \\
\text { When: - } \\
\text { Why: it causes lung cancer, heart disease, and stroke. }\end{array}$} \\
\hline 4. Topic & \multicolumn{3}{|c|}{ Cigarette smoking causes deathly diseases. } \\
\hline 5. Introduction & \multicolumn{3}{|c|}{$\begin{array}{l}\text { Strong sentences: } \\
\text { Cigarette smoking increases risk for death from all causes in men and women. The } \\
\text { risk of dying from cigarette smoking has increased over the last } 50 \text { years in men and } \\
\text { women. } \\
\text { Thesis statement: } \\
\text { Cigarette smoking causes deathly diseases, such as lung cancer, heart disease, and } \\
\text { stroke. }\end{array}$} \\
\hline 6. Body & \multicolumn{3}{|c|}{ 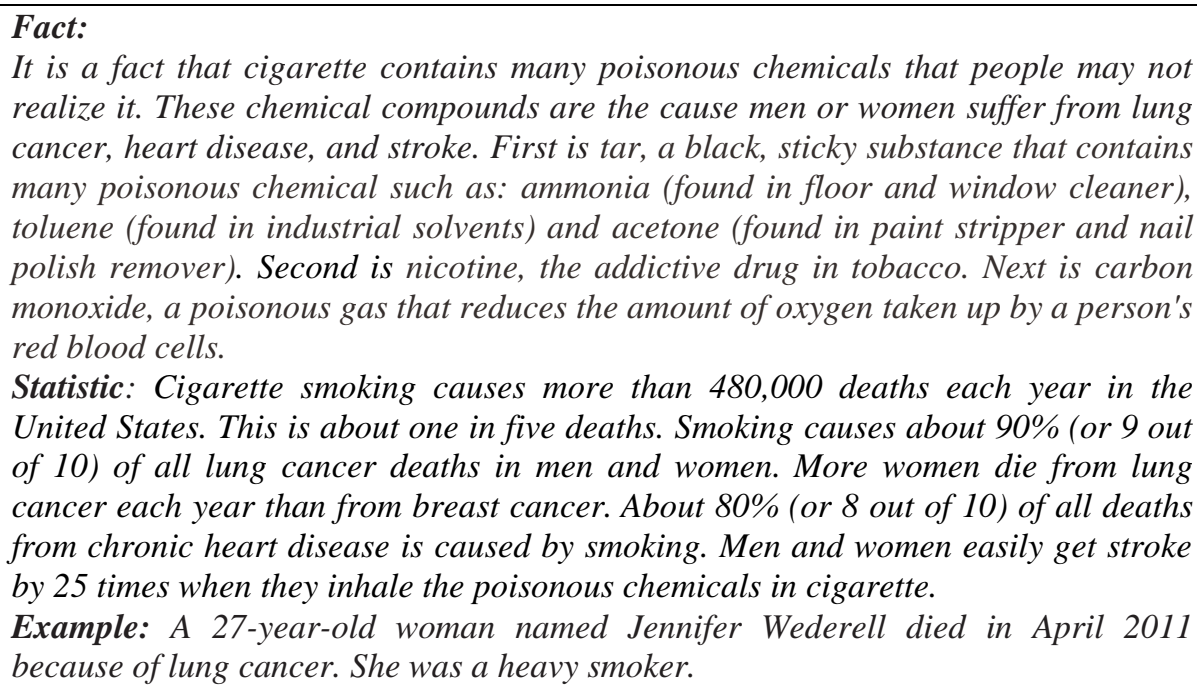 } \\
\hline 7. Conclusion & \multicolumn{3}{|c|}{$\begin{array}{l}\text { Recommendation/ suggestion: If nobody smoked, one of every three cancer deaths } \\
\text { would not happen. Men and women must be happy and healthy for Quitting smoking } \\
\text { lowers the risk for smoking-related diseases and can add years to the life. }\end{array}$} \\
\hline
\end{tabular}

The example of student writing above shows how persuasive technique is applied in chronological order using template in order to arrange a good writing. The draft also indicates that the six strategies help the student to find the best topic to be discussed and 
organize the sentences in coherence. The draft becomes a complete persuasive essay as it is also given the lecturer's input.

Cigarette smoking causes deathly diseases.

Cigarette smoking increases risk for death from all causes in men and women. The risk of dying from cigarette smoking has increased over the last 50 years in men and women. Cigarette smoking causes deathly diseases, such as lung cancer, heart disease, and stroke.

It is a fact that cigarette contains many poisonous chemicals that people may not realize it. These chemical compounds are the cause men or women suffer from lung cancer, heart disease, and stroke. First is tar, a black, sticky substance that contains many poisonous chemical such as: ammonia (found in floor and window cleaner), toluene (found in industrial solvents) and acetone (found in paint stripper and nail polish remover). Second is nicotine, the addictive drug in tobacco. Next is carbon monoxide, a poisonous gas that reduces the amount of oxygen taken up by a person's red blood cells. Cigarette smoking causes more than 480,000 deaths each year in the United States. This is about one in five deaths. Smoking causes about $90 \%$ (or 9 out of 10) of all lung cancer deaths in men and women. More women die from lung cancer each year than from breast cancer. About $80 \%$ (or 8 out of 10) of all deaths from chronic heart disease is caused by smoking. Men and women easily get stroke by 25 times when they inhale the poisonous chemicals in cigarette. One of many victims is a 27-year-old woman named Jennifer Wederell died in April 2011 because of lung cancer. She was a heavy smoker.If nobody smoked, one of every three cancer deaths would not happen. Men and women must be happy and healthy for Quitting smoking lowers the risk for smoking-related diseases and can add years to the life.

Lecturer's input: the content gives a complete series of fact, example, and statistic to support the body of paragraph. However, suggestion on the last paragraph should be explained deeper. There should be not only quitting smoking as the solution. The example of smoker, Jennifer can be as a case to find out the solution, such as lungs implant.

The example of student writing above shows the effectiveness of using persuasive strategy. The result of analyzing the student writing as follows.

1. Brainstorming

The strategy of involving the ideas in brainstorming help the students to get the easiest way in setting the most suitable title for the academic writing. The first step in brainstorming is related to free writing in which all 
the ideas flow freely and develop into logical and acceptable for academic demand. In free writing, all the ideas can be written in rough draft on the template. The way of putting all the ideas is analyzed by the lecturer to know the effectiveness of the persuasive strategy. Furthermore, when a student finds out the specific topic, then he/she can decide what main points go into the essay. In order to get the right topic for academic writing, the students do free writing in which they spend a predetermined period of time writing all the flowing ideas in mind on a paper until they decide one topic that will be discussed in the writing essay. The topic is about Health Problem or Healthy Lifestyle. In other word, brainstorming can help to choose a topic, develop an approach to a topic, or deepen the understanding of the topic's potential.

2. Mapping

The second phase of organizing the ideas is mapping. In changing the general topic into representative one, mapping technique is used in order to make classification on the aspects that related to the title. Brainstorming is different with mapping in this writing concept. Brainstorming is the technique to get the title of the essay writing. Whenever a student has no idea that comes up with, brainstorming is recommended to call the background knowledge. According to the student practices on mapping technique, it is concluded that mapping is breaking down the topic into levels. The topic as the result of brainstorming is explained into specific subtopic. The strategy of mapping in persuasive essay as below.

(1). Change the general topic into specific subtopic. Words or phrases are allowed in

describing more detail information under a particular topic.

(2). Words or phrases are complementary in which the chosen phrases represent the

the most suitable topic for the development of paragraph.

3. The $5 \mathrm{~W}$ 's

The purpose of concept $5 \mathrm{~W}$ 's is to create the important content for the introductory paragraph, body and conclusion. The concept consists of asking the writer about who has been analyzed, what has been analyzed, the background of the 
problem, and conclusion which is suggestion. The $5 \mathrm{~W}$ 's gives imaginary of complete paragraphs that will be written. This means the writer will know what to do in organizing the ideas, words, and phrases and what to write in coherence sentences. In addition, the student as the writer won't get stuck or less ideas. This step is also called as planning of the final draft in which becomes understandable and logical topic. The topic becomes the headline of the content of paragraphs.

4. Introduction: providing thesis statement.

Introductory paragraph is started with strong statement to support the form of thesis statement. The statement is used in order to attract the attention of the reader to read meaningfully and to persuade them in understanding the crucial thing of medical cure or health solution. Furthermore, thesis statement makes the topic be clearer and tells the related content for the next sentence building. The thesis statement contains meaningful words that represent the medical academic writing that will be discussed the issue, fact, and example on the next step of writing.

5. The body of paragraph: providing fact, data statistic, and example for the body of paragraph

The advantage of providing fact, data statistic, and example is to support the body of paragraph. By knowing what to write, writing becomes smoothly flow and the ideas will come up directly. Providing fact is essential in order to ensure the reader the content of essay which may suggest the knowledge of definition of a disease, chemical compound in a medicine, and practical term for medical cure. Data statistic is used in proving the reader the benefit of a certain suggested solution. In addition, example is given to share the real testimony of people who do the right thing for healthy lifestyle.

6. Conclusion: giving solution and recommendation

In summarizing the essay, the student should provide some suggested medical treatment or cure for the topic that he/she discussed. The recommendation is gained from the fact, data, and example which support in summarizing the final statement as the key points of medical point of view. 
The result of using persuasive strategy on student writing practices gives impact on the student composition. The application of brainstorming, mapping, the $5 \mathrm{~W}$ 's and sentence coherence on the introduction, body, and conclusion gives the students some ideas for persuasive essay. The health topic that twenty five students of medical have as follows.

\begin{tabular}{|l|l|l|l|}
\hline No & The Health Topic & No & The Health Topic \\
\hline 1 & Cigarette smoking & 14 & Breast cancer \\
\hline 2 & Obesity & 15 & Eye infection \\
\hline 3 & Plastic surgery & 16 & Hearing loss \\
\hline 4 & Junk food & 17 & Stroke \\
\hline 5 & Yoga & 18 & Heart attack \\
\hline 6 & Aids & 19 & Narcolepsy \\
\hline 7 & Cloning & 20 & Osteoporosis \\
\hline 8 & Headache & 21 & Diabetes \\
\hline 9 & Gastric flu & 22 & Drug abuse \\
\hline 10 & Down syndrome & 23 & Alcohol drinking \\
\hline
\end{tabular}

Most students felt enthusiastic to follow teacher instructions and were willing to participate in the learning activity. From the observation sheets and teacher input on student paper, it is shown that the students are motivated to follow teacher instructions. The activity in learning persuasive strategy and applying them on their writing essay, engage students in independent action, which is designed to connect academic knowledge with some fact, example, and data to achieve a meaningful purpose and understandable written message for the reader. The strategy of applying Mapping and the $5 \mathrm{~W}$ 's improve the student skill in creating thesis statement.

(1). Cigarette smoking causes deathly diseases.

(2). Obesity increases the children health problems

(3). Plastic surgery is high prize and

(4). Junk food can damage your liver and heart.

(5). Yoga prevents cancer and improves the mental health.

(6). Contaminated blood transfusion and breastfeeding from mother to child cause AIDS

(7). Pro and contra of cloning the animal

(8). Headache as the result of head trauma and tumor.

(9). Avian flu in birds and poultry may affect humans. 
(10). Children born with down syndrome can lead productive lives

(11). The modern treatment for breast cancer prevention

(12). Avoid the contact lenses use! very quickly damage your eyes.

(13). The prevention and the cure of hearing loss

(14). Tobacco smoking, diabetes, and high cholesterol are the causes of stroke

(15). The symptoms and treatment of heart disease.

(16). The symptoms and solution for narcolepsy

(17). Calcium and vitamin D prevent bone loss

(18). Gastric bypass surgery has been successful in patients with diabetes

(19). Drug abuse can lead to drugged driving, violence and stress.

(20). Car accident related to alcohol use

(21). Diarrhea cause of infant deaths worldwide

(22). Asthma causes chest tightness, shortness of breath, and coughing.

(23). Anorexia nervosa causes dizziness, headaches, drowsiness, and fever.

(24). A serious depression leads someone to do suicide.

(25). Smallpox has killed people than all other infectious diseases

The suggested input used by the lecturer should cover the important of student writing expectation. This is a positive input for improving the student writing at the next level. The lecturer may criticize the content or highlighting the stages that the students need to improve. Some may be given suggestion on the sentence building and word choice, but the others may be given the input on the topic or thesis statement. In evaluating the student writing, evaluation essay checklist is used and the result as the guideline for the lecturer to give input and correction on the student essay. Here is the example of evaluation check list for criticizing the content of student essay.

\section{Table 4}

The Result of Evaluation Essay Checklist

Name of student: A Topic: cigarette smoking

Thesis statement: cigarette smoking causes deathly diseases

\begin{tabular}{|c|l|}
\hline $\mathbf{V}$ & $\begin{array}{l}\text { EVALUATION ESSAY CHECKLIST } \\
\text { criteria? }\end{array}$ \\
\hline $\mathbf{V}$ & Is the topic clearly stated in the thesis statement, and does it reflect the \\
\hline
\end{tabular}




\begin{tabular}{|c|c|}
\hline & impression made? \\
\hline $\mathbf{v}$ & $\begin{array}{l}\text { Are the content of essay logical? Are there any fact, data statistic and } \\
\text { example? }\end{array}$ \\
\hline $\mathbf{v}$ & $\begin{array}{l}\text { Are the sentences put in coherence? Are the ideas arranged in } \\
\text { chronological order? }\end{array}$ \\
\hline- & Does the conclusion state the solution and recommended findings? \\
\hline
\end{tabular}

Based on the result of evaluation checklist above, it is shown that the essay that the student made has followed the strategy of writing persuasive essay. The essay has reasonable and clear topic, thesis statement, and coherence between sentences. By using this checklist, the lecturer confidently gives positive input on the student paper. Below is the example of lecturer's input related to the topic of cigarette smoking.

Lecturer's input: the content gives a complete series of fact, example, and statistic to support the body of paragraph. However, suggestion on the last paragraph should be explained deeper. There should be not only quitting smoking as the solution. The example of smoker, Jennifer can be as a case to find out the solution, such as lungs implant.

This evaluation checklist really helps the lecturer in giving a positive input for the student writing improvement. The lecturer has the analysis and basic reason for putting some ideas on the input. The suggested correction above shows critical thinking on the content of the student essay. The lecturer doesn't correct the grammatical error and vocabulary; mostly it is on the ideas, sentence coherence, and the connection between introductory paragraph, body and conclusion. This is what the lecturer prefers to give on correction because the medical students hope to be corrected on the content rather than the grammatical or vocabulary errors. However, one example of student essay above shows that there is a weakness on the student's writing a conclusion. There is no clear solution in solving a problem of cigarette smoking. Providing some solutions for cigarette smoker isn't enough if there is a single way. The lecturer has given another recommended suggestion which is related with the example, fact, and data analysis in the body of paragraph. It can be concluded that the writing persuasive essay contributes the students to write a complete stage started from creating topic, thesis statement, introduction, and body of paragraph until the last finding of formulating some recommended solutions of medical treatment or healthy lifestyle. In addition, writing persuasive essay has 
contributed in finding the relevant fact, analysis, and example to support the content of paragraph. The relevant findings are gained by the students by doing some effort in reading, discussing, and consulting.

\section{Discussion}

Some benefits of using the strategy writing persuasive essay have been experienced by both student and lecturer. The technique is easy to be used, very clear to be done, and applicable. The strategy of using brainstorming, mapping, the 5 W's, composing the thesis statement, fact, data statistic, example, and recommendation solution have given impact on the student writing improvement.

(1). The topic is relevant with the health issue

(2). The words or phrases are arranged by using mapping for sentence building

(3). The thesis statement represents the whole content of paragraphs

(4). The fact, statistic, and example are logical and related to the discussion.

(5). The conclusion has recommended findings and solutions

In addition to dramatic improvements in student and lecturer writing experiences, the strategy of persuasive essay presents these following advantages.

(1). Students enjoy writing

(2). Students write significantly more

(3). Low students often make as much progress as high students

(4.) Students work independently with significantly greater on task performance

(5). Overall literacy improves across a broad range of reading, writing, and thinking skills

(6). Students gain confidence

(7). Students demonstrate more accountability and demonstrate greater effort

(8). Students know how to write good persuasive essay

(9). The lecturer gives positive input on the student writing

(10). Writing subject has completely fulfilled the student and lecturer writing expectations. 


\section{Conclusion}

Writing persuasive essay has been practiced in all subjects especially in Medical academic writing. The strategy of making persuasive essay promotes the applicable stages of finding the relevant topic, thesis statement, paragraphs, and conclusion. In addition, the students are asked to make a good writing which has the criteria of sentence coherence, related and logical findings. The findings in conclusion are expected to give some recommendation in health issue. Furthermore, this detail step can help the student to organize the ideas and sentences in paragraph into chronological order.

The strategy of brainstorming and mapping contribute in setting the most suitable topic. In these stages, the students are helped when they are in the midst of searching what to be discussed on the paper. The $5 \mathrm{~W}$ 's are applied in order to get the words or phrases which complete the topic become a thesis statement. The paragraphs written in the essay are in coherence the fact, statistic, example and the conclusion are stated in chronological order. As it is a persuasive writing, the conclusion conveys the findings on health issue that the student writes as the topic. The findings should give the readers some benefits solution of health problem.

The evaluation essay checklist means to get the input is acceptable for the students thought so that they know which part of writing skill that have to be improved. The evaluation focuses in suggesting the content and organization of the idea. This input is considered to be meaningful for the medical student as they expect to be corrected on the content rather than on grammatical or vocabulary errors. This checklist makes the lecturer easily analyzes the weaknesses on student writing so that the input given is relevant with the evaluation criteria.

The purpose of using the strategy of persuasive essay is giving the valuable practices in writing for student and guideline in writing input for the lecturer. The techniques which are promoted in the persuasive essay consistently improve the student writing performance, student confidence in putting the ideas, and the skill of writing solution for health problem. The method of evaluating the content of essay also enhances the lecturer's skill in providing some inputs based on the students' 
expectation for their academic writing. It proves that a good writing requires some techniques to have a readable and understandable persuasive essay.

\section{References}

Anderson, L.W \& Krathwohl, D. R. 2001. The Taxonomy Table' in A Taxonomy For Learning, Teaching and Assessing: A Revision of Bloom's Taxonomy of Educational Objectives. New York: Longman

Bennie, M. 2009. A Guide to Good Business Communication. Oxford: Spring Hill House.

Daniels, H. 1999. New Standards For Teaching and Learning in America's Schools. Heinemann

Ferris, D. 2002. Treatment of Error in Second Language Student Writing. Ann Arbor: University of Michigan Press.

Hyland, K. 2002. Teaching and Researching Writing. Harlow: Longman.

Hyland, K. 2003. Second Language Writing. New York: Cambridge University Press.

Johnson, B. E. 2002. Contextual Teaching and Learning: Why It Is and Why It Is Here to Stay. California: Sage Publications Ltd.

McCarthy, T. 1998. Descriptive Writing. New York: Scholastic Professional Books.

Rao, V. 2007. A Visual Guide to Essay Writing. England: James Cook University.

Smith, M. 2000. The Art of Composition: Writing The Essay. New York: Cambridge University Press

Starkey, L. 2004. How to Write Great Essays. New York: Learning Express

Stiggins, R. 1996. Assessing Writing. Addison-Wesley: Longman.

Zainuddin. 2004. Teaching English as a Foreign Language in Indonesia. Journal of English Teaching. (Volume XV). 